$$
\text { NAG } 3-337
$$

NASA Technical Memorandum 88934

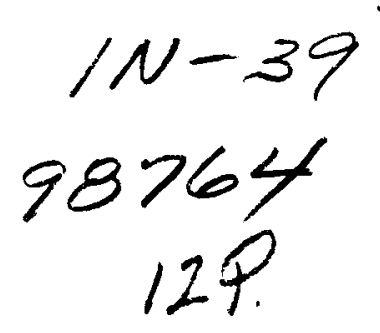

\title{
Exposure Time Considerations in High Temperature Low Cycle Fatigue
}

S. Kalluri and S.S. Manson

Case Western Reserve University

Cleveland, Ohio

and

G.R. Halford

Lewis Research Center

Cleveland, Ohio

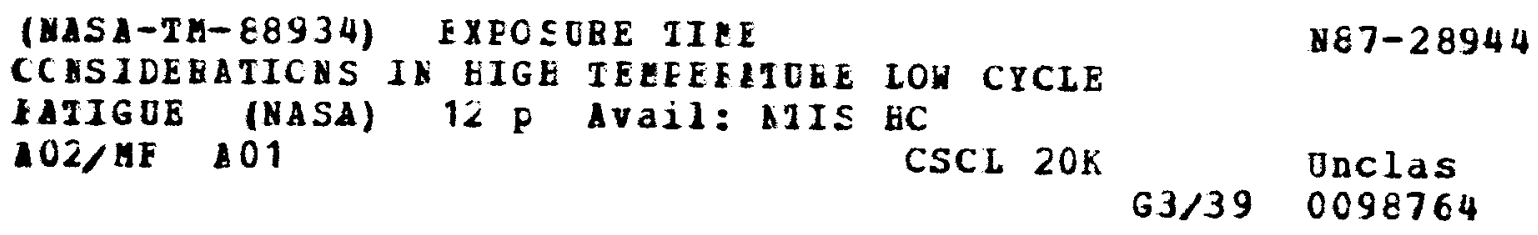

Prepared for the

5th International Conference on Mechanical Behaviour of Materials cosponsored by the Chinese Society of Metals and the Chinese Society of Mechanics Beijing, China, June 3-6, 1987

\section{Nusn}


EXPOSURE TIME CONSIDERATIONS IN HIGH TEMPERATURE LOW CYCLE FATIGUE

\author{
S. Kallurik and S.S. Manson \\ Dept. of Mechanical and Aerospace Engineering \\ Case Western Reserve University \\ Cleveland, Oh10 44106 U.S.A \\ and \\ G.R. Halford \\ National Aeronautics and Space Administration \\ Lewis Research Center \\ Cleve?and, ohto 41 ? 35 U.S.A.
}

\title{
ABSTRACT
}

The Conventional Strainrange Partitioning (CSRP) method for HighTemperature. Low-Cycle Fatigue (HTLCF) life prediction has its origins in the modeling of first-order, creep-fatigue waveform effects while treating as second-order effects, the influence of metallurgical or enviranmental time dependencies. Procedures are proposed to include these time dependencies explicitiy in the inelastic strainrange--life relations. For brevity. only the $C P$ life relation $w 117$ be presented in detail. The exposure-time effect within the CP inelastic strainrange (tensile creep reversed by compressive plasticity) was determined by tensile stress hold-time experiments for 316 SS at $816{ }^{\circ} \mathrm{C}$. Reductions in CP cyclic 1 ife of a factor of about two were observed with an increase in exposure time or a corresponding decrease in creep rate by a factor of about 100. The cP iffe relation has been modified to be expressed in terms of either Steady State Creep Rate (SSCR) or Exposure Time (ET). The applicability and accuracy of the timedependent $C P$ life relations is demonstrated by conducting verification experiments involving complex hysteresis loops. Metallographic examination revealed time-dependent degradation attributable to oxide formation and precipitation of carbides along grain boundaries.

\section{KEYWORDS}

Creep-fatigue; Life prediction; Strainrange partitioning; Steady state creep rate; Exposure time; Ductility; Stainless steel.

\section{INTRODUCTION}

The Conventional Strainrange Partitioning (CSRP) method for HighTemperature, Low-Cycle Fatigue (HTLCF) recognizes waveform of loading as

*Presently at Sverdrup Technology, Inc., Lewis Research Center, Cleveland, ohto 44135 U.S.A. 
the primary variable governing cyclic life, and distinguishes among waveforms of loading that give rise to generic inelastic strainranges of $\Delta \varepsilon p p$, $\Delta \varepsilon_{c p}, \Delta \varepsilon_{p c}$, and $\Delta \varepsilon_{c c}$ (Manson, Halford, and Hirschberg, 1971). A separate life relation is generated for each type of strainrange. If more than one generic strainrange component is present in a hysteresis loop, the cyclic life can be calculated using an Interaction Damage Rule (Manson, 1973). However, under prolonged exposure at elevated temperature, environmental effects and metallurgical instabilities may a ter the mechanical properties and hence reduce crack initiation resistance. Modeling time dependencies is essential for reliable life predictions, particularly for long-time exposure encountered by equipment such as used for electric power generation.

The nature of creep damage depends upon the magnitude of the creep parameters. Priest and Ellison (1980) utilized creep rate to identify the domains of dominant mechanisms in the creep process. Since creep rate is inversely related to the time of exposure, it can be utilized in determining the effect of exposure time on the creep-fatigue $11 \mathrm{fe}$. Manson and Zab (1977) suggested a modification of the CSRP 11 fe relations which involved addition of a time-dependent term. However, no experiments were conducted to establish the nature of the time-dependent term. In the absence of experimental cyclic results, time-dependent changes in ductility observed in creep tests can be incorporated into the Ductility Normalized Strainrange Partitioning (DNSRP) life relations (Halford, Hirschberg, and Saltsman, 1977; Manson, 1973) to predict time-dependent creep-fatigue lives. These life relations utilize the piastic and creep ductilities, $D_{p}$ and $D_{c}$. They account for exposure time by using the creep ductility corresponding to the exposure time of the creep-fatique test. It is proposed herein that either steady State Creep Rate (SSCR) or Exposure Time (ET) be used to modify the Conventional CP life relation in an effort to incorporate time effects directly within the Strainrange partitioning framework.

EXPERIMENTAL RESULTS

Solid, hourglass specimens of 316 SS were tested in air at $816{ }^{\circ} \mathrm{C}$ under computer control in a servo-hydraulic testing machine. Strain-controlled testing at $0.2 \mathrm{~Hz}$ (sinewave) resulted in the following equation for PP cycling:

$$
N_{p p}=0.521\left(\Delta \varepsilon_{p p}\right)^{-1.60}
$$

A conventional idealized $C P$ hysteresis loop is presented in Fig. 1(a), whereas the hysteresis loop utilized in the current study is shown in Fig. $T(b)$. The ratio of the creep strain (CD) to the inelastic strainrange (BF) was maintained at 0.6 in these experiments. Different exposure times were obtained by changing the magnitude of the tensile creep stress. The experimental detalis are presented elsewhere (Kalluri and Manson, 1984). The hysteresis loops were partitioned into the generic PP and CP strainranges considering oniy the steady state portion of the creep strain as creep (Kalluri, 1987; Manson, Halford, and Nachtiga 11, 1975). The Interaction Damage Rule was used to calculate the $C P$ generic cyclic life. The results of the conventional interpretation (no time dependencies considered) of the CP experiments are presented in $\mathrm{Fig} .2$. The equation shown is the least square fit of the eight data points, and hence averages the results. It is clear that at a given strainrange the cyclic life decreases with increasing exposure time. 

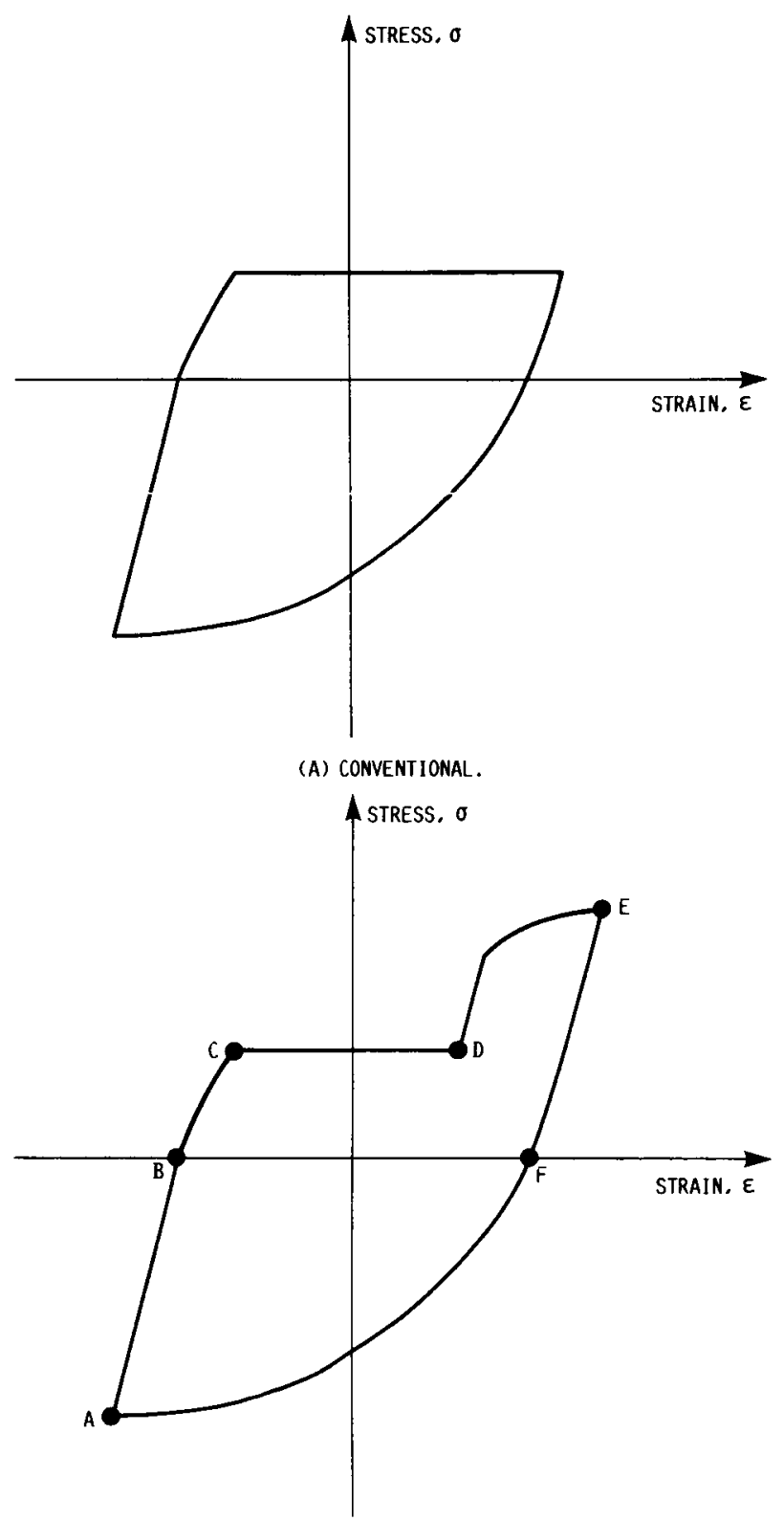

(B) GEMERAL IZED

FIGURE 1. - CP HYSTERESIS LOOPS. 


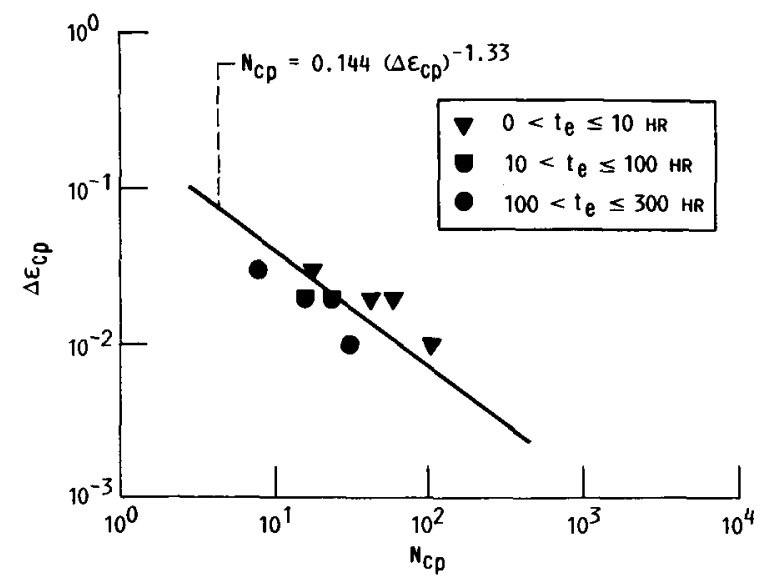

FIGURE 2. - CONVENTIONAL CP LIFE RELATION, 316 SS AT $816^{\circ} \mathrm{C}$.

The data presented in Fig. 2 were also used to establish the Steady State Creep Rate (SSCR) and Exposure Time (ET) Modified life relations by consideration of the time dependencies. The 11 fe relations established by multiple linear regression are as follows:

$$
\begin{gathered}
\text { SSCR: } \quad N_{C P}=0.646\left(\Delta \varepsilon_{C p}\right)^{-1.46}\left(\dot{\varepsilon}_{S S, T}\right)^{0.256} \\
\text { ET: } \quad N_{C P}=0.113\left(\Delta \varepsilon_{C p}\right)^{-1.63}\left(t_{e}\right)^{-0.332}
\end{gathered}
$$

where

$$
\begin{array}{ll}
\Delta E_{C P} & \text { the generic } C P \text { strainrange } \\
N_{C D} & \text { the generic CP cyclic life } \\
\dot{\varepsilon}_{S S, T} \text { tensile steady state creep rate, min-1 } \\
\text { te } & \text { total exposure time of the creep-fatigue test, } \mathrm{hr}
\end{array}
$$

The SSCR Modified ( $N_{C p}^{\prime}$ ) and ET Modifled ( $\left.N_{c p}^{\prime}\right)$ generic cyclic lives (aS defined in Fig. 3) are plotted against $\Delta c_{c p}$ in Figs. 3(a) and (b), respectively. These figures clearly indicate that the SSCR and ET Modified $C P$ If waveform of loading.

For comparison with life predictions by the Ductility Normalized SRP method, creep-rupture experiments at $816{ }^{\circ} \mathrm{C}$ determined the degradation of creep ductility, $D_{c}$ (based on reduction of area at rupture), to vary with rupture time, $t_{r}$, according to

$$
D_{c}=2.40\left(t_{r}\right)^{-0.140}
$$

In accordance with the recommended Ductility Normalized SRP Procedure, $t_{r}=t_{e}$, and the time-dependent Ductility Normalized SRP life relation for CP strainrange is given as,

$$
N_{c p}=0.0512\left(\Delta \varepsilon_{c p}\right)^{-1.67}\left(t_{e}\right)^{-0.140}
$$



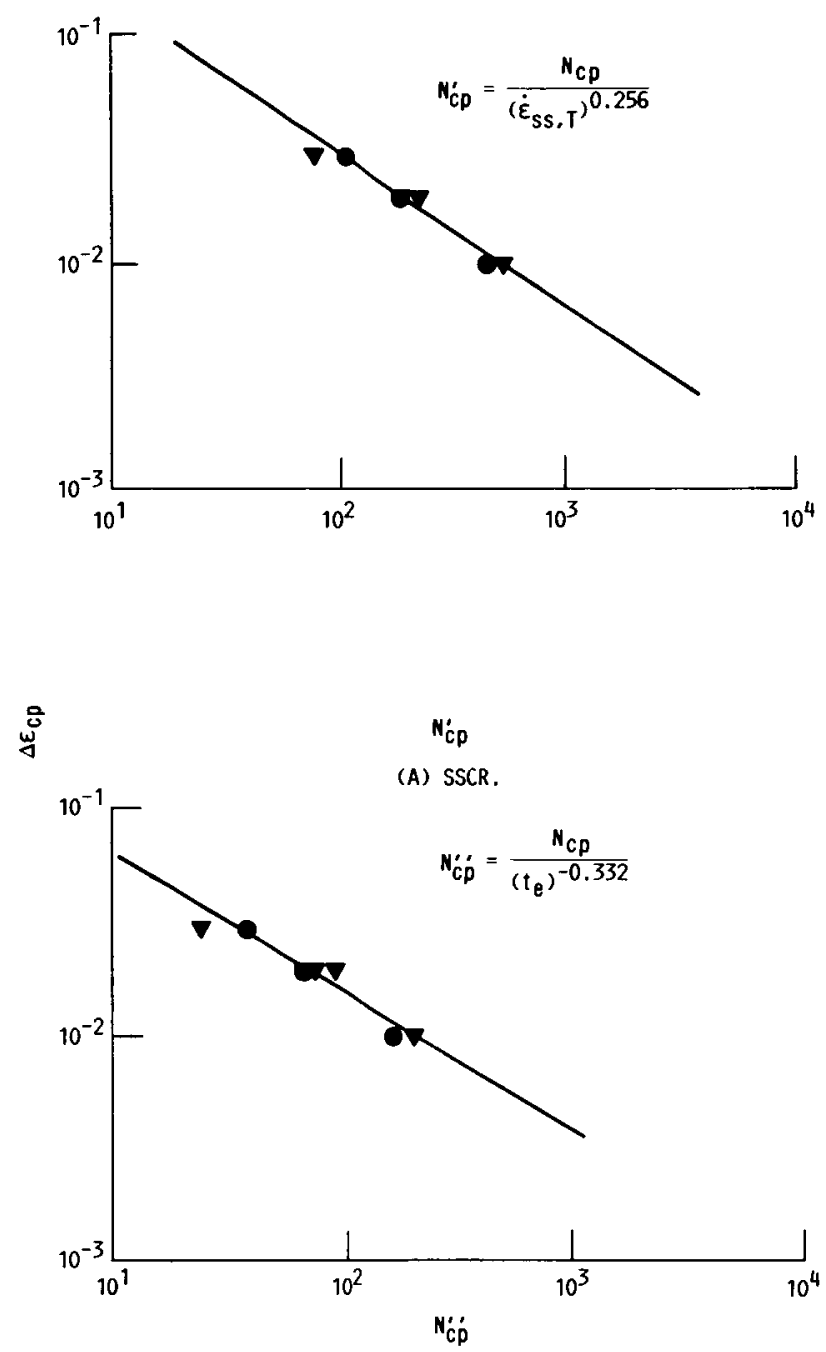

(B) ET.

FIGURE 3. - MODIFIED CP LIFE RELATIONS. 316 SS AT $816{ }^{\circ} \mathrm{C}$.

The above CP IIfe relations will now be applied to independent verification experiments. Three types of experiments involving PP and CP strainranges were conducted at $816{ }^{\circ} \mathrm{C}$. These are classified as $C P$ with (1) small amounts of tensile creep strain, (2) creep at two stress levels and (3) ramping creep stress. Life predictions were made using the Conventional CP 11 fe relation, the CP life relation as given by Eq. (5), and the two newly established CP 11 fe relations (Eqs. (2) and (3)). In all cases, the PP 1 iffe relation and the Interaction Damage Rule were used in conjunction with the $C P$ IIfe relation to calculate the cyclic lives. These results are presented in Figs. 4 to 6 along with a schematic of the hysteresis loop of each verification test. Results of all three types of verification experiments indicate predictions by Conventional SRP to be conservative at short exposure times and unconservative at long exposure times. Thus, calculations based on the CSRP life relations would dangerously overpredict creepfatigue lives for very long exposure times. Both the Steady State Creep 

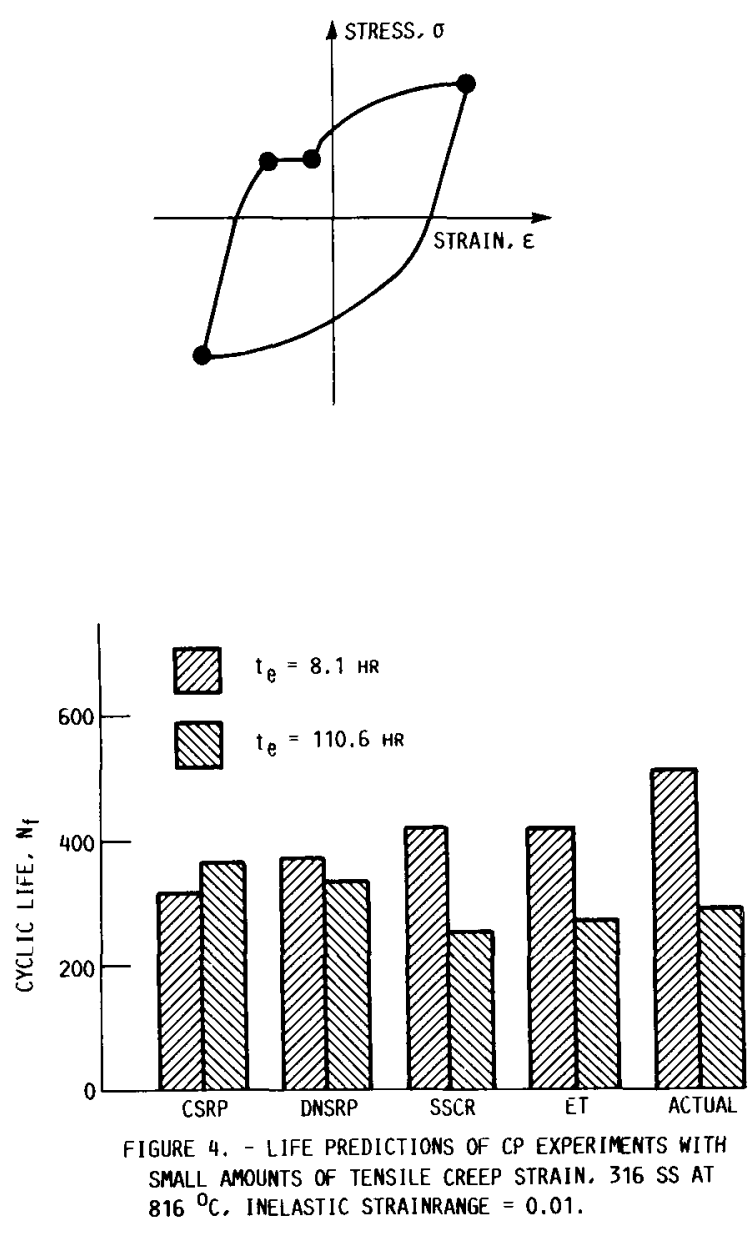

Rate and Exposure Time Modified CP life relations closely predicted the cyclic verification lives. The Ductility Normalized SRP predictions reflect some time dependency and lie between the conventional SRP, SSCR, and ET Modified life predictions.

\section{DISCUSSION}

In the past, attempts were made to include the effect of exposure time on the High Temperature Low Cycle Fatigue (HTLCF) life by incorporating the frequency of the cycle in the life relations. For example, Coffin (1970) developed the Frequency Modified Life relation (FML) to predict fatigue $11 \mathrm{fe}$ at elevated temperatures. FML does not consider the effect of waveform of loading per se on the HTLCF life, and models a mixture of PP and CC waveforms together with the exposure-time effect of the CC waveform. Kalluri and Manson (1984) utilized the FML for predicting the cyclic lives of the CP life relation experiments. For $316 \mathrm{SS}$ at $816^{\circ} \mathrm{C}$, 11fe predictions were unconservative by more than a factor of 3 . The lack of 

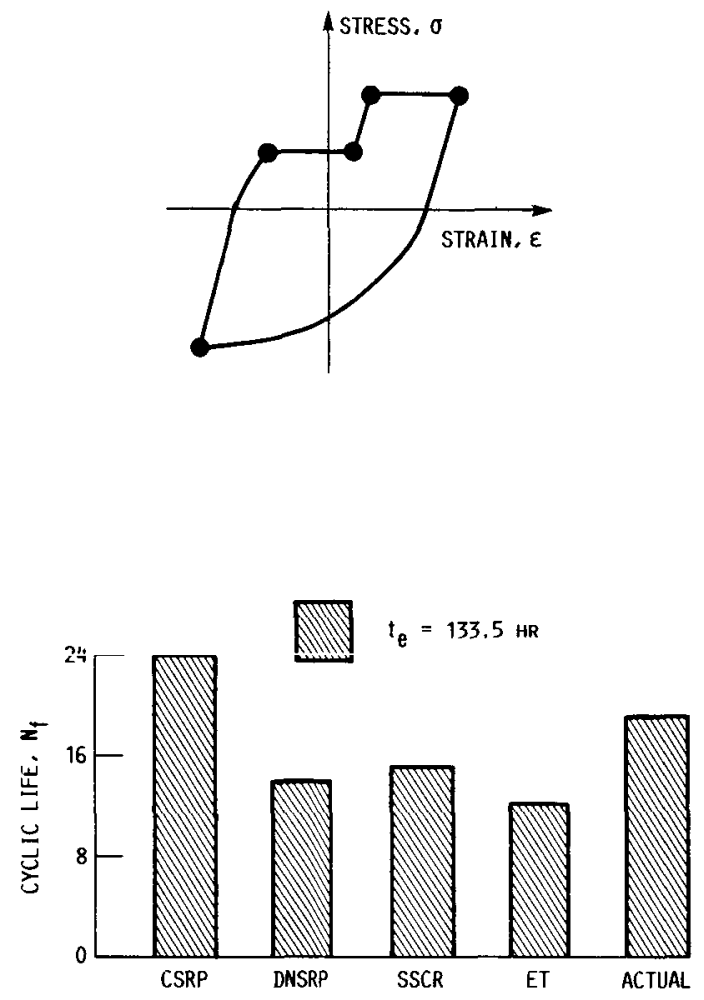

FIGURE 5. - LIFE PREDICTIONS OF A CP EXPERIMENT WITH CREEP AT TWO STRESS LEVELS. 316 SS AT $816{ }^{\circ} \mathrm{C}$. INELASTIC STRAINRANGE $=0.03$.

agreement appears to be due primarily to the waveform difference between $C P$ and CC strainranges rather than due to exposure time. Frequency Modified Life predictions presuppose a CC waveform.

The Frequency Modified Life relation and other methods fall short of accurately predicting the creep-fatigue life, because they do not consider the individual effects of the waveform and exposure time. The Ductility Normalized SRP method has a provision to treat the exposure time effect, and hence, predictions are better than the ones by Conventional SRP. The Steady State Creep Rate (SSCR) and Exposure Time (ET) Modified CP 11 fe relations characterize the influence of exposure time within the CP strainrange in a distinct manner. Therefore, the predictions by these life relations are superior to the predictions of the other life relations considered in this study. The SSCR- and ET-Modified CP life relations also accurately predicted the lives of the complex hysteresis loops used in the verification experiments. Since verification experiments involved complexities not found in the baseline study, we have also demonstrated the versatility of the newly proposed life relations. For example, results of linear-time ramping of creep stress are shown to be accurately predictable. Nonlinear time variations of creep stress, such as stress relaxation during a tensile strain hold, etc., while not demonstrated, can be handled by the newly proposed equations. In this study, the exposure time effect within the waveform assoctated with the $C P$ strainrange has been established. Exposure 

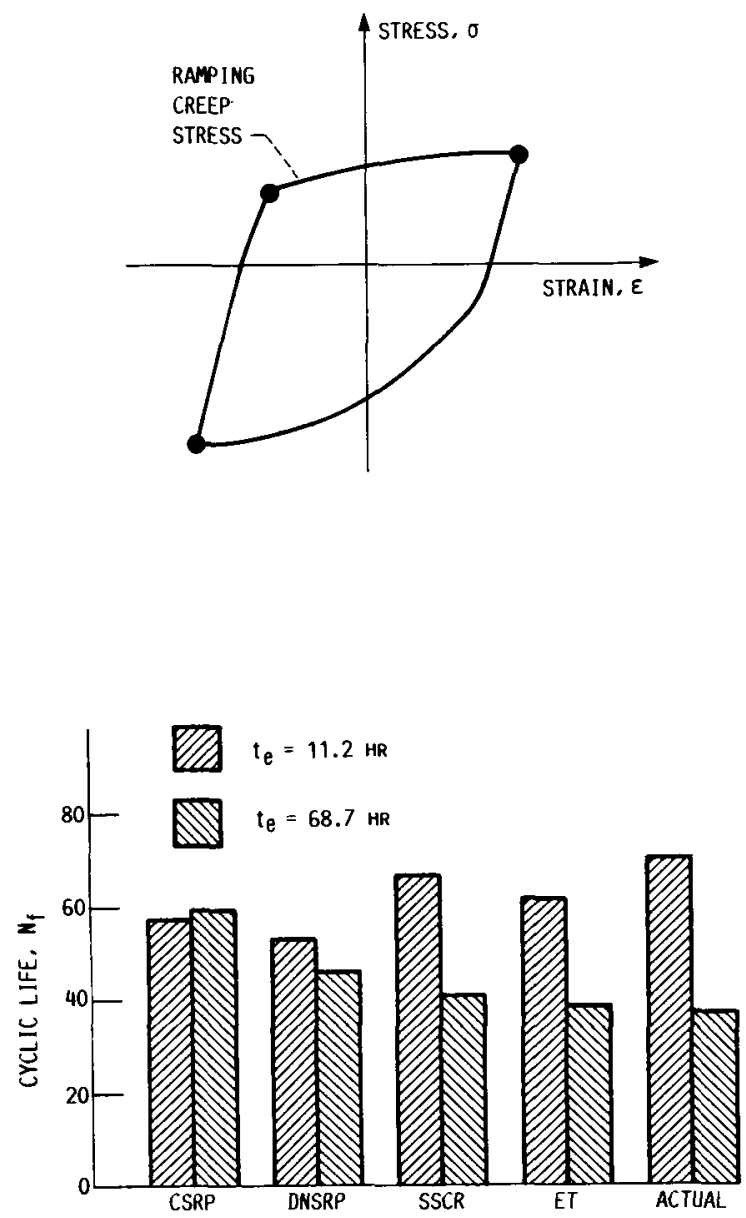

FIGURE 6. - LIFE PREDICTIONS OF CP EXPERIMENTS WITH RAMPING CREEP STRESS, 316 SS AT $816{ }^{\circ} \mathrm{C}$. INELASTIC STRAINRANGE $=0.02$.

time influences on the $P C$ and $C C$ strainrange 11 fe relations $w 117$ be published at a later date.

The nature of the damage associated with a long exposure time CP test is significantly different from that associated with short exposure time test. Metallographic investigations were conducted on the fractured specimens to study micromechanistic features. Metallographic sections of the short-and long-exposure CP tests are presented in Fig. 7. The short exposure time test is free of precipitates. Substantial amounts of chromium carbide precipitation, intergranular cracking, microvold formation and oxidation are clearly evident in the long-exposure time $C P$ test. The metallurgical instabilities in austenitic 316 SS at high temperatures were reported by Weiss and stickler (1972). For exposure times of the order of a few hundred hours at $816{ }^{\circ} \mathrm{C}$ carbide precipitation $\left(\mathrm{M}_{23} \mathrm{C}_{6}\right.$ type) is the major metallurgical instability. In the absence of any mechanical loading, grain boundary coarsening occurs due to the precipitation of the carbides along the grain boundaries as the exposure time is increased. This sensitizes 


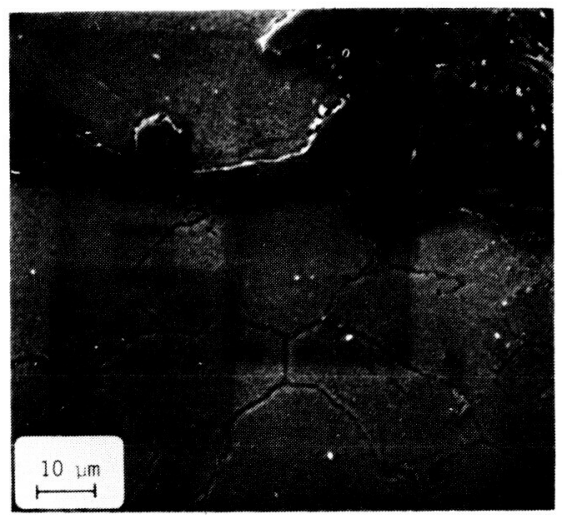

(A) $\mathrm{t}_{\mathrm{e}}=\overline{3.5 \mathrm{HR}}$

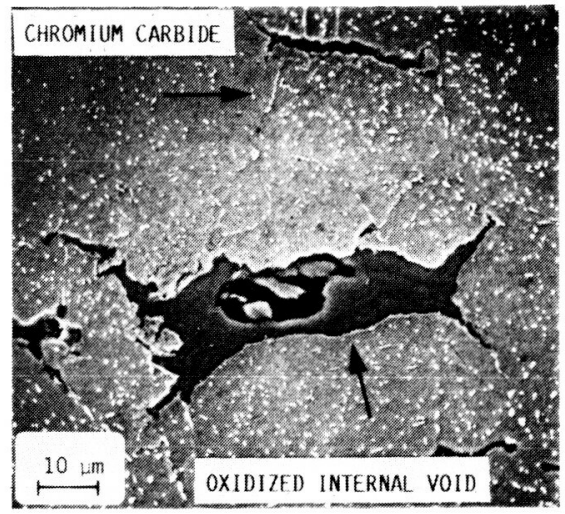

(B) $\mathrm{i}_{\mathrm{e}}-95.6 \mathrm{HK}$

Figure 7. - Metallographs of CP life relation experiments, 316 SS at $816{ }^{\circ} \mathrm{C}, \Delta \varepsilon_{\text {in }}=0.02$. etched in Marble's reagent.

the steel and increases its susceptibility to intergranular fracture. The carbides tend to prevent grain boundary sliding during creep. Deformation in creep is achieved by fracturing the grain boundary carbides. This phenomenon is more likely to occur in a long exposure time test, since sufficient time is available for carbide formation. For $316 \mathrm{SS}$, the above mechanism appears to be the major cause for the reduction in the long-time CP cyclic life. Kalluri (1987) discussed in detail other possible mechanisms. It should be noted that other materials may not display metallurgical instabilities or their instabilities may be due to other mechanisms. Thus, additional analytical representations of time effects may be necessary. Also, because of the time limitations in this program, the tests conducted were limited to exposure times of $300 \mathrm{hr}$. It is necessary to extend the tests to longer times for some long-time applications to determine if the power law variation is adequate for representation of material degradation for such cases.

\section{CONCLUSIONS}

The exposure-time effect with the CP strainrange of the Conventional SRP method was established by a series of creep-fatigue experiments on 316 SS at $816{ }^{\circ} \mathrm{C}$. Two new time-dependent life relations, the SSCR- and ET-

Modified CP life relations are developed. The accuracy and the versatility of the life relations are established from the results of the verification experiments conducted with complex hysteresis loops. The reduction in the cyclic life of the $C P$ experiments at long exposure times is attributed to the interaction of cyclic strain and the precipitation of chromium carbide, oxidation and internal damage due to microvoid formation. 
Coffin, Jr. L.F. (1970). The effect of frequency on high-temperature low cycle fatique. Proc. Alr Force Conf. on Fatique and Fracture of Aircraft Structures and Materials, AFFDL TR 70-144, 301-311.

Halford, G.R., J.F. Saltsman, and M.H. Hirschberg, (1977). Ductility normalized-strainrange partitioning life relations for creep-fatigue life predictions. In M.R. Louthan and R.P. McNitt (Eds.), Environmental Degradation of Engineering Materials, Virginia Tech. Printing, Blacksburg, VA, PD. 599-612.

Kallur1, S. and S.S. Manson. (1984). Time dependency of strainrange partitioning $11 \mathrm{fe}$ relationships. Case Western Reserve University, Cleveland, Ohio, NASA CR-174946, pp. 1-62.

Kalluri, S. (1987). Generalization of the strainrange partitioning method for predicting high temperature low cycle fatigue ilfe at different exposure times. Ph.D. Dissertation, Case Western Reserve University, Cleveland, $\mathrm{OH}$.

Manson, S.S., G.R. Halford, and M.H. Hirschberg (1971). Creep-fatigue analysis by strain-range partitioning. In S.Y. Zamrik (Ed.), Design for Elevated Temperature Environment, ASME, New York, NY, pp. 12-24.

Manson, S.S. (1973). The challenge to unify treatment of high temperature fatigue - a partisan proposal based on strainrange partitioning. In A.E. Carden, A.J. MCEvily, and C.H. Wells (Eds.), Fatigue at Elevated Temperatures. ASTM. Philadelphia, PA, PD. 744-782.

Manson, S.S., G.R. Halford, and A.J. Nachtigall (1975). Separation of the strain components for use in strainrange partitioning. In S.Y. Zamriek and R.I. Jetter (Eds.), Advances in Design for Elevated Temperature Environment. ASME, New York, NY, DD. 17-28.

Manson, S.S. and R. Zab (1977). A framework for estimation of environmental effect in high temperature fatigue. In M.R. Louthan and R.P. McNitt (Eds.), Environmental Degradation of Engineering Matertals, Virginia Tech. Printing, Blacksburg, VA, PD. 757-770.

Priest, R.H. and E.C. Ellison (1980). Estimation of cyclic creep damage by strain and strain rate considerations. In International Conference on Engineering Aspects of Creep, 1980-5, vol. 1, Inst. of Mech. Engrs.. London, pp. 185-192.

Weiss, B. and Stickler, R. (1972). Phase instabilities during high temperature exposure of 316 austenitic stainless steel. Metall. Trans.. 3 , $851-866$. 


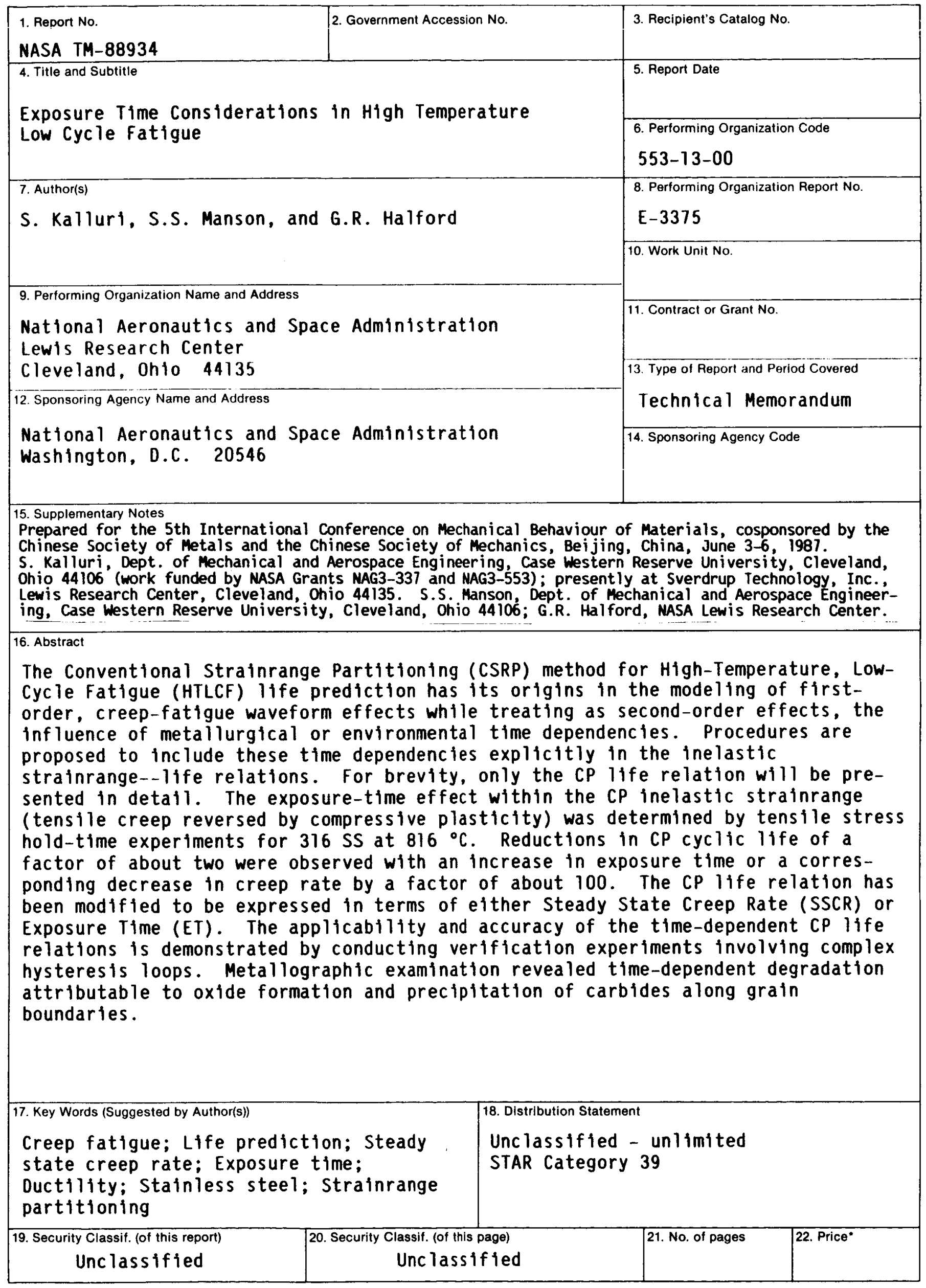

*For sale by the National Technical Information Service, Springfield, Virginia 22161 